\title{
Hume and Kant and Managers Epistemology. An Interview with Paul Griseri
}

\author{
Wim Vandekerckhove ${ }^{1}$ D
}

Received: 31 August 2021 / Accepted: 8 September 2021 /Published online: 22 September 2021

(c) The Author(s) 2021

\begin{abstract}
This article is a transcript of an interview with the previous editor-in-chief of Philosophy of Management (2010-2017). It discusses his career, the use of and hopes for field of philosophy of management, and leading the journal.
\end{abstract}

Keywords Journal editor · Management $\cdot$ Philosophy

Paul Griseri was the editor-in-chief of this journal from 2010 until 2017. Paul indicated he wanted to meet less with the editors and instead spend more time making music. The editorial team wanted to thank Paul for leading the journal through an important phase, and put him in the spotlight. We couldn't do it during an annual conference because of COVIDrestrictions, so I caught up with Paul - on video call during lockdown early 2021 - and here is what we talked about.

Wim: You have been leading the Journal for a while and then you stepped down to form the band, and I'm guessing now it's lockdown so I don't think you're doing many shows. Any chance we can get you back on the Journal?

PAUL: Well I'm not active academically so while I'm happy to give support as appropriate, if there are papers to be reviewed, I could well be out of date in some ways. I think that's my main reservation. I'm not adverse to helping in whatever way I can but - obviously being out of academic circles, I don't have direct access to papers until they've got open access. And even with philosophy of management there's not that many that are on open access. But as I said when I stepped down, I'm more than happy to help out. But I don't think I'd want to go back to a regular presence at editorial meetings for example.

Wim: Is there anything you miss about academia?

PAUL: Is there anything I've missed? Well obviously being in a classroom with students, particularly small groups. It's not that I didn't like large lecture theatres but large lecture theatres when you're lecturing to 100 plus, sometimes 300 plus people, it's a certain kind of performance. And you know that some of them aren't really following what you're saying and the questions always come from the 10-15 really keen ones

Wim Vandekerckhove

w.vandekerckhove@greenwich.ac.uk

1 University of Greenwich, Park Row, London SE10 9LS, UK 
at the front. And if you ask them to have done reading, often they haven't and so on. Whilst in small groups, when I actually taught Philosophy of Management at Middlesex University, I only had ten people, ten undergraduates in my class and that was fantastic. It was absolutely brilliant because you could really engage, and these were not top flight students because of the way that Philosophy of Management had been treated in the pecking order, we often got people who didn't know what third year options to take. And they'd take it because they didn't know what it was. But then at the end of it all, they all said 'oh yeah, it's so different fromeverything else we do'.

So I did enjoy that side of things. I think - I didn't mind being a head of department in some ways when I was dealing with members of my team. And I kind of miss that interaction with people though obviously no one could possibly miss the admin, perhaps some people might miss the admin but I can't imagine very many would.

In terms of research, I didn't really do very much. I did enjoy writing those monographs or the introduction to Philosophy of Management but I wasn't a researcher in the sense of ever really getting involved in projects. People used to try and get me involved and I'd kind of 'oh no, I don't fancy that'. My career as a researcher might be rather better - certainly when I was at UCL a couple of professors tried to get me involved in things and in retrospect it's probably naïve of me, I said 'no thanks!' But there you go.

Wim: At UCL you were Director of Studies, Management and Innovation?

PAUL: Eventually, yes. I started off as a part timer and then it grew to being a larger part timer, and then there was a change from it being a centre to a department. And then I said to the new head of department 'well you're looking for a director of studies, I'll do it'. So I actually only did it for about a year or 18 months. And that was basically administering the undergraduate provision, that's what I was doing.

Wim: Actually your background is - you were first a philosopher and then you moved into business, or then you moved into management studies.

PAUL: Yes, that's right.

Wim: So what is your PhD about?

PAUL: Well my PhD was called The Master of the Passions and it was an examination of the relationship between Humean and Kantian views of the role of reason in action and obviously particularly the role of reason in ethical choice. I'm not sure that I would be able to summarise exactly the main point of it, but I was more or less arguing a position similar to McDowell in a way. That reason can enter into choices, not simply as being a means to an end that's independently desired or needed or wanted, but it actually can play a role in the formulation of motives and intentions and desires. In other words, the springboards for choice.

I did my first degree which I finished in 1974, a BA in Philosophy, and then I did a few odd jobs and then I was a schoolteacher for 10 years. And I realised I wasn't cut out for school teaching, I didn't have the confidence to deal with difficult mid-teens. And it was at that point that I enrolled to do my doctorate at the University of Kent in 1983. But then in 1986 somebody I knew who was running a diploma in management studies (DMS) said 'oh you ought to come and do this, you might find it really useful'. So I was doing 2 courses as well as working full time; I was doing my diploma in management studies and my $\mathrm{PhD}$ at the same time as working.

I finished the two of them more or less simultaneously and the college that I'd done the DMS at said 'you ought to come and teach here' and I wanted to get out of school teaching. So I said 'alright I'll come along'.

So I did a couple of years teaching DMS students and then one of my colleagues there was setting up a management training company and I did that for a bit. And then I decided 
I wanted to move back to education. So I went to what was then Luton College of Higher Education, I think it's now the University of Bedfordshire. And then I moved on from there to London Guildhall University, now part of London Met. But I was mainly teaching HR type subjects at the time and doing a little bit of reading around business ethics but still ponding about what Philosophy could contribute to management.

And it was only at the end of the 1990s, early 2000s that I came into contact with Nigel Laurie, which was intriguing because I think I'd seen him on a website and made contact with him. But then we discovered we had a link in that both he and I had been taught by somebody called Chris Cherry. Chris Cherry had taught Nigel when he did his Masters in Glasgow; he's a philosopher, Chris Cherry and he'd been my $\mathrm{PhD}$ supervisor at Kent University. Chris had helped Nigel set up the Journal in the first place and I had a couple of meetings with him. So that's how I got involved.

Wim: So it was actually during your PhD in Philosophy that someone suggests that you need to look into management studies.

PAUL: Yes, that's right, but not as a result of doing the PhD, it was just somebody I knew socially who said 'oh I think if you're head of a department in a school you might want to think about this'. And then he asked me to facilitate a group I think and he said 'oh you're good at this, you ought to do your DMS and we'll see if we can get you teaching'. In fact that particular person said 'I don't know why you're doing that $\mathrm{PhD}$ in Philosophy, it's never going be of any use to you!' That's the long view!

Wim: Just for clarity, what is DMS?

PAUL: Diploma in Management Studies, postgraduate pre Masters, like a diploma but without the dissertation. Although they did do a small project. So it would be the equivalent - do you still use M points?

Wim: No. Well at least I don't.

PAUL: They used to say well a Masters was $120 \mathrm{M}$ points, a $\mathrm{PhD}$ was $360 \mathrm{M}$ points and a postgraduate diploma was 80 or $90 \mathrm{M}$ points as a sort of measure of the volume of learning I guess.

Wim: I think they now call it credits.

PAUL: Yes, credits.

Wim: It's the same.

PAUL: Mickey Mouse calibration you could call it really.

Wim: And you said you were wondering how the philosophy could be useful for the management studies. So it's not like you're managing and you run into a management problem and that makes you go to the philosophy. It seems to be like: we love philosophy, we happen then to, by coincidence, end up in management or management studies. And then say 'oh, how can I use that?' because we want to but not because we see the need. Or am I presenting this the wrong way?

PAUL: Well I think you characterise it very well. Of course characterising it that way creates a massive question mark about whether the discipline is necessary unless you are a philosopher, which is intriguing. Clearly business ethics has found a niche and it's entrenched itself, though probably not in the way that I would have liked to have seen it entrenched. To be honest I haven't really looked at the JBE for some time but I got the impression that Ed Freeman was going to try and take it a little bit more philosophically. It's not that it doesn't have philosophical stuff, but the last times I looked there still was more a more social science side to it.

So business ethics always had a niche because there are always ethical questions about management, and those ethical questions could have sometimes a direct professional purchase because if you did the wrong thing you could find yourself in court. Or you could 
certainly find that your brand loses any kind of customer appeal because you've done horrible things to your employees or something like that.

Whereas philosophical questions about the nature of organisation, the nature of knowledge, the nature even of leadership don't necessarily have quite the same direct impact. They have a sort of broader contextual value I think. Whether you think of an organisation as a corporate person or as a loose aggregation of people's intentions doesn't necessarily affect whether you're going to install a new computer system or launch a new product as such, whereas a business ethical issue could do.

So I think that it doesn't directly impact business actions, but then certainly in the analytic tradition, philosophers used to be very keen on saying Philosophy should leave things as it is. I don't think that's right personally but there was certainly a very strong trend of that in the twentieth century in Britain and the United States at least. So I think that is a challenge, in Philosophy of Management, why bother at all? There are lots of other things we could do to ameliorate business, rather than philosophy.

I think it's probably something that really ought to be taught on PPE courses. I say that because PPE is certainly a relevant course in Britain and there are parallel things in other countries - almost self consciously trying to prepare the leaders, the political leaders of tomorrow. And there are relevant phenomena like the growth of precarious workforce and highly distributed responsibility ... outsourced and shell companies and holding companies and companies that end up getting bought by hedge funds that don't really do very much except try and profiteer from them. All those sorts of things that create question marks about the nature of organisation and what it means to use a noun for an organisation. What kind of noun is it? What kind of thing is an organisation?

And those are things that won't necessarily affect day to day management choices but certainly at the level of, certainly of long term politician decision making, though not necessarily what some corrupt British prime minister wants to do to get himself out of a hole this minute. But what large multinational NGOs might be trying to do in the long term in terms of the impact of corporate life on human life, on areas such as culture, I think that's where the value of Philosophy of Management lies. And that's why I say that courses like the PPE in Britain or like those courses that are done at Sciences Po in Paris preparing senior civil servants and politicians for the French Government. That's where I think the value of Philosophy of Management should come.

Wim: So that's trying to show the usefulness or the value of Philosophy for people who are going to be managing or are going to be decision makers. Do you have any views on doing it in the opposite direction? So how do we make management and organisational decision-making appealing as a subject for philosophy students?

PAUL: That's an interesting question. My recollection is that occasionally philosophers might use corporate examples but often because they're academics with very little professional engagement with corporations, they deal with corporations as a customer or a client. But they would often have a naïve understanding about corporations. I think particularly Roger Scruton quite a long time ago, published an article in the Proceedings of the Aristotelian Society called Corporate Persons. And it's very intelligent and very well argued but at the end, he ended up saying 'a corporation is an abstract person' which actually to me, doesn't really explain anything, it just labels it, that's a different matter. But I remember reading it and thinking, he doesn't really know much about what goes on in organisations. He knows about universities but he doesn't really get it.

So I think that one of the issues is that like so many things, philosophers will talk about business without necessarily knowing much about the business. They'll talk about Art and of course some of them may well be artists, amateur or even professional artists, 
and musicians or actors. Though some of them won't. Kant wrote loads about Art and there's no evidence that he showed any interest in behaving as an artist.

Straightforwardly - well I would say this wouldn't I - it would be good to have an undergraduate course specifically for Philosophy students - the trouble is that Philosophy of Management is on management courses. And if you had a Philosophy of Management course for philosophers, for undergraduates, and just begin by presenting them with a management dilemma - for example, imagine you're suddenly pitched into running a team and there's a crisis and they're all looking round at you and asking you what to do. And trying to get them to get a sense of the experience of managing, even though it's still only a projected sense, it's not a real experience, it's only one that they might have perceived from the other side, from being managed rather than being a manager. Of course that's a little bit of a false dichotomy because anyone working in an organisation is managing to some extent, unless they're literally just sitting there with their eyes closed pressing a button every $2 \mathrm{~s}$, and that kind of work is increasingly done by robots. But the vast majority of people certainly in more developed societies, exercise some decision making for themselves, take some responsibility. So where somebody is called a manager, where they're not is a much more grey area now than it may have been in Ford's time for example.

But I think that certainly we should get Philosophy students to actually follow a course on Philosophy of Management, rather than a course on management, not an Introduction to Management because I don't think that would necessarily help so much. It might be an introductory course that involved some of those introductory things about e.g. basic functions and so on but very quickly moving to deeper questions about what do managers know? What does any of us know when we say that Facebook is this kind of company, or the $\mathrm{BBC}$ is very [he said patronising but said it wasn't the word he was thinking of] it acts like a parent, parental. What does that mean and how do we know it? And even where you draw the line and say 'this is Facebook'. Does that include every single person who goes in there and cleans the toilets, which in one sense it should do. But then that's probably not what people think.

So I think that exposing people to students to that experience would be important. I think there are still some huge epistemological and ontological issues that are still waiting to be explored in Philosophy of Management. So often philosophers certainly in the Anglo Saxon tradition labour to explain how I can look at a flower and say truly 'this is a flower'. And actually the complexity of organisational life and organisational decision making and organisational judgement is something that I think would actually be a source of inspiration for some philosophers.

Wim: Because it's a different kind of question than the question 'when do I know I know something?'

PAUL: Yes. Though it's related; the thing is that looking at, taking a sort of Kantian derived point of view (which would still be highly influential in my philosophical training through Hume and Kant and the Empiricists) very little can be said to be properly known in the strongest sense of the word, and yet managers have to deal with things instantaneously as if they know them. Obviously from a kind of Humean Empiricist point of view, you would say 'well they just believe it strongly' but the point is managers have to stake their reputation, their career, the jobs of others and the wellbeing of clients, very often on an almost instantaneous basis.

In some ways, I think what I'm trying to get at - is that the empiricist conception of knowledge is so constraining and I think we need broader ideas, but not going to a relativistic point of view that well, there is no truth. There is a truth, I believe strongly, I'm very 
much still a Kantian in that sense that there is one world, though we have a very imperfect engagement with it. But it's still there to be investigated and to be understood, it's just that it's bloody difficult. And I think organisationally engaging in organisations, whether as a manager, a worker, a client, supplier, tends to - it forces people past the ambiguities because you just have to get on with things. But on the other hand as a subject of enquiry, I think the world of business far richer than most of the material that philosophers use to certainly in epistemology, metaphysics, ontology and so on.

Wim: You're right. When I reflect back on my studies, very often when philosophers were going into discussing responsibilities connected to roles and a role where you'd say well at the same time you manage someone but you're also being managed. A position in a hierarchy, they would use the military as an example and so it's always extreme organisations that are used as an example. Or they would analyse a business dilemma and as an example work with 'your best friend' or 'your mother'. They rarely use examples from work life, you're not working with your best friends, you're not working for your mother. And they just - I certainly recognise what you are saying there, there's a lack of that, we need to get to the people who are teaching Philosophy, in universities as well.

If we come back to the Journal. So you were, as I see it, currently the Journal is published by Springer, it has a fantastic support, the backup support by Springer, it's really wonderful. I think when Nigel started it, he was running the Journal from his home. And that was it, and you're sort of like the pivot moving it from one place to then that nice institutional embedding. How long were you editor-in-chief?

PAUL: Well I'll sort of talk about it in general and answer that specific question. I think you're flattering me to describe me as the pivot. I quickly became Nigel's right hand man if you like, I think. But for a long time, Nigel was shouldering the main responsibility, not just getting articles reviewed and getting people to review them and so on. But also putting the copy together and getting them published, printed, distributed etc, and he did a huge amount. I can't imagine how he did it all.

And then, I can't remember exactly the order of events but I think before we started publishing with Libri - yes I'm sure it was before Libri - originally the idea was that we would have a sort of triumvirate of editors and each of us would take an issue sequentially. But that fell apart rather quickly and so I ended up by default being the editor in chief. And I suspect that must have been 2007/2008 maybe some time like that, I can't remember.

And then we decided we needed to have an academic publisher and because I'd started working at Middlesex University, I automatically thought of Middlesex University Press. Though when I approached them, it turns out that they were just about to be not exactly, well - privatised I think you might call it. The university decided to disassociate themselves from what was Middlesex University Press so the publisher had to call themselves something else - hence the name Libri. We were the only journal that they actually worked with initially, and I think both sides underestimated what was involved. But certainly that was our first step to having a proper publisher and they did the job as well as they could. I think maybe after that they did take on a couple of more journals but we were the first so they did a lot of learning, shall we say. And so did we.

But that was a great springboard for then to speak to Springer. We actually had about 3 offers and again that was all Nigel, it has to be said. Springer wasn't the only offer, I think we had at least 2 other offers, if not 3 offers on the table. And at the time we were making the decision, we didn't realise that Springer would work so closely with us and we kind of worried for a bit, whether we would just be talking to a large corporate entity? And I don't think that fear was realised at all actually, they seem to have been very responsive to us. The advantage of being with Springer of course is it's absolutely global player with huge 
infrastructure etc. And yes, once we'd spoken with Floor we were convinced that we would get the backup that we needed.

So that's how we got to that point. And I remained as editor until you took over, obviously, whenever that was, 2016 ?

Wim: I think we talked in 2016 and I actually took over in 2017.

PAUL: Although I was doing a lot of administration, Nigel was always there in the background as very wise counsel, in support.

Wim: I was just thinking, running a journal within academia it seems - when I said 'oh you know I'm editor in chief of a journal' they said 'ok you know, what's the impact factor?'

PAUL: Well there was always a lot of that and of course Philosophy of Management is never going to have a massive impact factor. It doesn't have a massive circulation. I certainly saw work that I thought had been influenced by things that we'd done but placed elsewhere - in fact I vividly remember somebody saying - he had come to one of the conferences in the early 2000, and he said 'yeah, I'm doing a paper'. And I said 'oh right, have you got your ....' He goes 'no I'm sending it to the Academy of Management Review'. And I remember saying 'why?' And he said 'well because it will get more exposure, it will be better for me'. So there was certainly that.

Wim: My approach to that, if someone develops their paper within one of our conferences or in the paper development workshop, whatever that we run. And then they are successful in publishing it and AMR, AMJ, AMD or whatever... I think that's fantastic! ok it's not a paper that we publish and it's obviously a very good paper but it brings attention to the subject and the field.

PAUL: Yes, you're absolutely right and .... I was perhaps speaking a bit parochially.

Wim: More people feeling confident that they can write a paper, doing a philosophical enquiry about something related to management. And if it's not AMR that's going to publish it they can send it to Philosophy of Management ...

PAUL: In that sense, the United States is actually a slightly better area for that than the United Kingdom because in the United States many people's first degrees are quite broad, liberal educations. And many of them may have done a little bit of Philosophy and therefore not see it quite so out of place. Whereas in the United Kingdom you end up specialising at 16, if not before 16, on paths that often build quite substantial walls between areas that you might be otherwise interested in. In France it's not so bad because for the baccalaureate they have to do a little bit of Philosophy in most versions of the bac anyway. So you do see more of an overlap between Philosophy and Management here than you do, say in Britain or Australia.

Wim: I just want to come back to your oeuvre because a lot of people will know you - certainly within the executive editors team we very regularly still speak about your Philosophy of Management book. I knew you had done one on CSR but there are many business ethics textbooks out there, whereas your Philosophy of Management, it's still quite unique. But then Nigel said 'yeah but Paul published many books before that'. I didn't know, sorry about that. You did In Search of Business Ethics 96, Management Values 98, Management Knowledge 2001, and 2010 the CSR book and then 2013 the Philosophy of Management. So how do you look back on that trajectory? How did you get to do those other books - was that your Philosophy of Management at that point?

PAUL: No, the very first one, it was actually a colleague who had got involved with a publisher who wanted what are called business reports, but they were books, and we wrote that together. We also later on wrote another textbook together on E-Business, of all things. 
I think with the Management Values one - there was still at the time this idea that organisations should go for shared values. Basically the book was meant to be a critique of shared values and so it was more psychology of morality rather than business ethics. It wasn't pure psychology but it was looking at the whole idea about values and how you can share values across an organisation, the shared behaviour and so on. And yes, I just approached Palgrave, then they were still MacMillan. I approached them because somebody I knew, he became a colleague at UCL, a bloke called Richard Pettinger who has published a zillion and ten introductory books on management subjects. And I said to him 'you published with MacMillan, what are they like?' And he said 'oh go to them and here's the person to contact'. So that's how that worked.

I think after that, although they knew that they weren't going to sell a lot or anything, they then said 'well do you have any other ideas?' And that's when I had the idea of Management Knowledge, which I think that's the nearest to actually achieving what I wanted to achieve. And I'm not bothered that it didn't really have much of an impact but I felt that I actually in that book managed to put something together that satisfied what I was trying to say, which was in effect - perhaps I should have made it more explicit - that knowledge doesn't come from one methodology, it comes from a whole variety of sources.

Steve Smith actually wrote a couple of papers on a similar vein, and he expressed it in a slightly more extreme way, but on the same track. Basically if there's a truth there, then you can get it from touching it, you can get it from seeing it and so on. So there's not one way to discovery. And I went through the various different theoretical views about knowledge and critically evaluated them. And I ended up with my own version of something like Habermas's Knowledge and Human Interests. And I basically said 'Habermas is right, though I think there's a little bit more to it than that' and I added a a flourish of my own, if you like. He talked about material interests and social interests and so on, and technical as well as material. And I said 'well there's also an aesthetic element as well to knowledge'. It's nice to see there's a bit of aesthetics now in the Journal isn't there? And I added a category to cover that, but basically the idea there was a different way of approaching the epistemology with regard to management. And I did try and make the case that other applied professions could make similar argument, say about education or about medical practice and so on. But it was very much about applied knowledge.

So I think that was the one that I thought was closest to my heart, before I wrote the Introduction to Philosophy of Management, though when I finished that, I wasn't really satisfied with the introduction; I think it was a bit unbalanced in some ways. And I think that, had they let me have an extra year I could have produced actually a book that was better integrated thematically. But I'm glad ........

Wim: There's a thematic imbalance?

PAUL: Yes, not enough on mind, for example. I think also there are certain parts of it, the writing of it could have been perhaps a bit more elegant as well. Though I don't have copies of any of these books now by the way, they all seem to have disappeared. I know the first couple I got complementary copies and, I was working at the time, they said 'oh, we need one for an exhibition of people's work'. And somehow that happened four times and I lost all my copies [hahaha]

I don't know if I've still got a copy of the Introduction here, I might have, I don't think I've got the CSR book.

Wim: If you imagine young scholars and who are interested in Philosophy of Management, but they're also in need of a job, what would your advice be to them?

PAUL: If someone needs a job, that's a hard question really. I think if they need a job, they have to think about which management sub disciplines are going to yield the kind of 
outcomes that they need to get them started, ie the right kinds of publications. And I would think that HR .......with business ethics are overdone frankly, so if they were to think about some of the wider aspects of strategic management and the philosophical issues relating to strategic management, I think that would be the most fruitful direction. Because that brings up questions of structure and the nature of what an organisation is. It brings up wider political and social considerations about what management does to civilisation. It also of course touches then on things like decision making and leadership and so on. So I think it's probably the more fruitful avenue than the HR one which I think is a bit restricted. Does that help?

Wim: Yes, it does. What is your experience of running the Journal, in the margin of being head of department and doing Philosophy of Management in a business school? What's your experience of that? How has it helped you?

PAUL: Well, it helped me personally in terms of teaching because even when I wasn't teaching directly a Philosophy of Management model but supervising doctorate students or teaching it had a relevance. I used to love teaching first year undergraduate Introduction to Management courses, or teaching things like contemporary issues in management, or bits of strategy and so on, and there were many ways in which Philosophy of Management came in. I think it helped immensely because one could take things further and particularly with something like International Management, getting people to understand different cultures and what it means to talk about understanding different cultures and where does cultural appropriation begin and what after all is a cultural identity. So in terms of teaching, I think it helped immensely in that respect and it certainly I think made my teaching a lot better than it would otherwise have been.

In terms of position within a business school, it wasn't much help really! But then - I think it depends on - not every business school is the same. I think there's room in places like Warwick and probably Greenwich too for that matter, for that sort of existence. Middlesex University, I don't want to be rude about it: after I stood down from being full time, I carried on there, part time for some time. But Phil of Management was always seen as an eccentricity; nobody really paid much attention to it. I think one of the professors in my department who was a professor of business ethics, he respected me for what I did. And I had a couple of other professors who acknowledged what I was doing. But in general it was seen as a bit of an oddity really. I don't mean that to be critical specifically of Middlesex University, I think that's probably true in other places I've worked and other places that I've been an external as well.

It just it wasn't on their agenda, they didn't really get it. However I never really encountered the kind of contemptuous dismissal of it that some people have related to me. I guess being an oddity can be a good thing so long as it's tolerated I think.

Wim: Thanks for taking the time for this talk, Paul. Is there anything I forgot to ask?

PAUL: I don't think there's anything you forgot to ask but I think before - I was thinking what areas do we still need to be working in? And I still feel that the study of management in general has never confronted its methodological shortcomings. I read an article in the Scientific American last year and they were pointing out that in natural science there is a huge - well a crisis really or at least a controversy. Because for so long people have relied on certain statistical presumptions and the more they've looked at them, they realised that they're actually not as reassuring as they should be. And the example that was given in this article, I can't remember the title of it, unfortunately I've chucked it away, I think it was about September/October 2019 if you wanted to look it up. But it said the idea that your $p$ value should always be at 0.05 or below and (I can't remember the details of the argument) he just said 'no it would depend on the context'. So while there might be a few cases where 
you could use it effectively, generally speaking it's not that good a guide as to the reliability of a statistical text.

Now that kind of thing is never thought about in management studies and I think that's one area that - and not just methodological design as such but also the care for truth that is involved - when I look at scientific articles, there is a care and almost the anxiety that they have that they will actually not just produce a well moulded piece of work but one that actually tells us something true about the world. That kind of methodological anxiety is absent in management studies; people do their work, adopting whatever methodology, they do it correctly, but after that there's no doubt about it. It's 'well I've done what I've done and that's it' and it's a contribution. Repeatability hardly occurs in management studies and certainly repeatability outside of a particular methodological organ is virtually unknown. Whereas in natural science, in physics, it's the first thing that happens. Someone writes a paper and within 3 months there will have been 10 attempts at repeatability, and those get written up. And failure of repeatability is written up (almost) as much as success in repeatability.

So I think that's one area that I think we haven't really engaged in sufficiently. Maybe the answer is that we shouldn't be thinking of management studies as science at all but then, a lot of people who practise it think of themselves as social scientists. And they want to adopt social science practices.

I think the other thing that I want to say is that - I think I've alluded to this several times really. The idea of what an organisation is, I think lots of people touch on it in lots of different ways. But somehow I think we are missing a trick about this. It feels to me that maybe some very old fashioned philosophical theories about ontology, realism as opposed to nominalism etc., might be ways to actually get at that. Even a platonic approach; I don't think we're mining the past enough and it's interesting that whereas Aristotle gets used a lot you don't often see papers that draw on Plato. You see more that draw on presocratic philosophies than on Plato, which is interesting.

So I think that's my little rant theoretically!

Wim: That's an area that's still under work, even in the Journal. Thank you very much Paul.

\section{Declarations}

Research ethics Data collection (the interview) for this article was collected with informed consent and in full compliance with the ethical principles of the Declaration of Helsinki.

Conflict of interest Wim Vandekerckhove declares that he serves as editor-in-chief of this journal. The peerreview process was coordinated independently from the editor-in-chief by an executive editor.

Open Access This article is licensed under a Creative Commons Attribution 4.0 International License, which permits use, sharing, adaptation, distribution and reproduction in any medium or format, as long as you give appropriate credit to the original author(s) and the source, provide a link to the Creative Commons licence, and indicate if changes were made. The images or other third party material in this article are included in the article's Creative Commons licence, unless indicated otherwise in a credit line to the material. If material is not included in the article's Creative Commons licence and your intended use is not permitted by statutory regulation or exceeds the permitted use, you will need to obtain permission directly from the copyright holder. To view a copy of this licence, visit http://creativecommons.org/licenses/by/4.0/.

Publisher's Note Springer Nature remains neutral with regard to jurisdictional claims in published maps and institutional affiliations. 